Lepr Rev (2000) 71, 246

\title{
Editor's Choice-September 2000
}

Many of you will be reading this issue of Leprosy Review at the Asian Leprosy Congress in Agra, India. To celebrate the congress we have published our largest issue ever of Leprosy Review with a record 11 papers. All the major leprosy endemic regions are represented. This is a tribute to all the work that is being done in our efforts to understand the disease and refine our management. We have papers ranging from the biochemical (looking at nitric oxide metabolites in reactions, p 355) through the epidemiological (the AMFES study, p 273) to the public health issue of predicting and understanding noncompliance ( $\mathrm{p} 369$ ). I hope that everyone will savour these articles. Many people have contributed in different ways to this issue and I would like to thank everyone who has worked so hard in the last few months bringing this issue to press.

The three editorials are all written from a global perspective. Maria Neira's article ( $p$ 247) outlines the World Health Organisation strategy, arguing that for some countries a more intensive strategy is needed. Terry Vasey's article (p 253) indicates how the Global Alliance can contribute to leprosy control. Leprosy research continues to be a priority at WHO and Paul Nunn (p 256) has outlined the thinking behind the Tropical Disease Research programme and I hope this will encourage people to apply for WHO funding.

Dominating this issue is a series of papers from the longitudinal AMFES study in Ethiopia. I decided to publish all these papers together to maximise their impact. This series represents a major success story for field workers, researchers and funders. Richard Croft (p 270) has written an overview highlighting the key points in the papers. This is the most comprehensive picture that we now have of the presentation and complications of leprosy in Africa.

I hope that the congress will generate more enthusiasm and that the post-congress papers will soon be reaching the Leprosy Review of fice.

DIANA N. J. LOCKWOOD

Leprosy Review has been informed of the death of Professor He Daxun, Vice President of the China Leprosy Association, on August 2, 2000 in Beijing after a short illness. He was 69 years old.

\section{Leprosy Poster}

Leprosy: Differential Diagnosis No. 2 Nodules. (McDougall/Patience). We would like to thank the Wellcome Tropical Medicine Resource for providing the images of onchocerciasis (Professor A. Bryceson). Kapos: Sarcoma (Dr M. Rolfe). Molluscum contagiosum (W.K. Jacyk), mycetoma (Dr M. Rolfe). Professor A. Bryceson provided the image of diffuse cutaneous leishmaniasis. 